\title{
Biomechanical fixation properties of cortical versus transpedicular screws in the osteoporotic lumbar spine: an in vitro human cadaveric model
}

\author{
Charles A. Sansur, MD, MHSc, ${ }^{1}$ Nicholas M. Caffes, BS, ${ }^{1}$ David M. Ibrahimi, MD, ${ }^{1}$ \\ Nathan L. Pratt, MD, ${ }^{1}$ Evan M. Lewis, MD, ${ }^{1}$ Ashley A. Murgatroyd, BS, ${ }^{2}$ and \\ Bryan W. Cunningham, $\mathrm{PhD}^{2}$
}

'Department of Neurosurgery, University of Maryland School of Medicine; and ${ }^{2}$ The Orthopaedic Spinal Research Institute, Department of Orthopaedic Surgery, University of Maryland St. Joseph Medical Center, Baltimore, Maryland

\begin{abstract}
OBJECTIVE Optimal strategies for fixation in the osteoporotic lumbar spine remain a clinical issue. Classic transpedicular fixation in the osteoporotic spine is frequently plagued with construct instability, often due to inadequate cortical screw-bone purchase. A cortical bone trajectory maximizes bony purchase and has been reported to provide increased screw pullout strength. The aim of the current investigation was to evaluate the biomechanical efficacy of cortical spinal fixation as a surgical alternative to transpedicular fixation in the osteoporotic lumbar spine under physiological loading.

METHODS Eight fresh-frozen human spinopelvic specimens with low mean bone mineral densities (T score less than or equal to -2.5) underwent initial destabilization, consisting of laminectomy and bilateral facetectomies (L2-3 and L45), followed by pedicle or cortical reconstructions randomized between levels. The surgical constructs then underwent fatigue testing followed by tensile load to failure pullout testing to quantify screw pullout force.
\end{abstract}

RESULTS When stratifying the pullout data with fixation technique and operative vertebral level, cortical screw fixation exhibited a marked increase in mean load at failure in the lower vertebral segments $(p=0.188,625.6 \pm 233.4 \mathrm{~N}$ vs 450.7 $\pm 204.3 \mathrm{~N}$ at $\mathrm{L}-4$ and $p=0.219,640.9 \pm 207.4 \mathrm{~N}$ vs $519.3 \pm 132.1 \mathrm{~N}$ at $\mathrm{L}-5$ ) while transpedicular screw fixation demonstrated higher failure loads in the superior vertebral elements $(p=0.024,783.0 \pm 516.1 \mathrm{~N}$ vs $338.4 \pm 168.2 \mathrm{~N}$ at $\mathrm{L}-2$ and $p=0.220,723.0 \pm 492.9 \mathrm{~N}$ vs $469.8 \pm 252.0 \mathrm{~N}$ at L-3). Although smaller in diameter and length, cortical fixation resulted in failures that were not significantly different from larger pedicle screws $(p>0.05,449.4 \pm 265.3 \mathrm{~N}$ and $541.2 \pm 135.1 \mathrm{~N}$ vs $616.0 \pm 384.5 \mathrm{~N}$ and $484.0 \pm 137.1 \mathrm{~N}$, respectively).

CONCLUSIONS Cortical screw fixation exhibits a marked increase in mean load at failure in the lower vertebral segments and may offer a viable alternative to traditional pedicle screw fixation, particularly for stabilization of lower lumbar vertebral elements with definitive osteoporosis.

http://thejns.org/doi/abs/10.3171/2016.2.SPINE151046

KEY WORDS cortical screws; transpedicular screws; osteoporosis; pullout; lumbar spine

$\mathrm{F}$ ORTY-FOUR million people in the United States suffer from osteoporosis, ${ }^{22}$ a condition that frequently affects the vertebral column and severely limits daily function and quality of life. Targeted therapeutic interventions for osteoporosis-associated spinal abnormalities are lacking. ${ }^{2}$ The diseased vertebrae limit cortical purchase with traditional transpedicular fixation, and many spinal fixation procedures are fraught with premature instrumentation failure as a result of screw loosening. ${ }^{7,8} \mathrm{New}$ tech- niques that maximize screw-bone purchase in osteoporotic vertebral segments may improve long-term surgical outcomes and patient quality of life.

As spinal implants evolved, pedicle screw fixation became the method to which all other fusion techniques are compared. Classic transpedicular screws follow a lateral to medial trajectory along the anatomical axis of the pedicle and engage a greater portion of cancellous bone than cortical bone. Cancellous bone is less dense, provides less sta-

ABBREVIATIONS BMD = bone mineral density; 6DOF-SS = 6-degree-of-freedom spine simulator .

SUBMITTED September 4, 2015. ACCEPTED February 25, 2016.

INCLUDE WHEN CITING Published online May 13, 2016; DOI: 10.3171/2016.2.SPINE151046. 
bility, is more flexible than cortical bone, and undergoes significant degeneration in osteoporosis. The purchase of cancellous bone compromises screw-bone interface strength $^{10,11,25}$ and has been implicated in pedicle screw loosening. ${ }^{6,11}$ Studies have either attempted to alter implant design ${ }^{1,9,20}$ or reinforce vertebral bodies ${ }^{3,16}$ to enhance bony fixation; however, few studies have evaluated novel implant trajectories that target the highly dense cortical bone.

The cortical screw may present a viable alternative to pedicle screws for posterior fixation of osteoporotic vertebral segments. First described by Santoni et al., ${ }^{22}$ the entry point for cortical screws is more medial than that for traditional pedicle screws, with a sagittally and cranially oriented trajectory, thereby purchasing the pedicle through the highly dense pars interarticularis (Fig. 1). This trajectory maximizes cortical and subcortical contact and may theoretically improve long-term segmental fixation and stabilization. Previous studies have reported equivalent uniaxial pullout strength of cortical screws, ${ }^{22}$ and biomechanical models of physiological stress resulting in instrumentation failure indicate that cortical screws have superior resistance compared with traditional pedicle screws. ${ }^{4}$ However, no study has compared the fixation strength of cortical and traditional pedicle screws in osteoporotic lumbar specimens following physiological loading. The objective of the current investigation was to apply multidirectional flexibility loading conditions followed by screw pullout testing to compare the efficacy of cortical spinal fixation as a surgical alternative to transpedicular fixation in the osteoporotic lumbar spine.

\section{Methods}

\section{Specimen Preparation}

Eight fresh-frozen human spinopelvic specimens (T10-ilium) obtained from the Maryland State Anatomy Board were harvested en bloc and used in this investigation. Prior to biomechanical analysis, standard anteroposterior and lateral fluoroscopic images were obtained to exclude specimens demonstrating intervertebral disc or osseous pathology. Bone mineral density (BMD) scans were conducted, and osteoporotic specimens were selected based on mean T scores (L-2 through L-5) less than or equal to -2.5 . In preparation for biomechanical testing, the T10-L1 vertebral bodies and ilium were secured in rectangular tubing foundations using eight 4-point compression screws. Five Plexiglas motion detection markers were placed on the anterior aspects of the L-2, L-3, L-4, and L-5 vertebral elements, and an additional marker was placed on the container base. The markers were equipped with 3 noncolinear light-emitting diodes designed for detection by an optoelectronic motion measurement system (3020 OptoTrak System, Northern Digital Corporation).

\section{Specimen Reconstructions}

The cortical and pedicle screw reconstructions were randomized between the L2-3 and L4-5 vertebral levels in each specimen. Following analysis of the intact spine condition, each specimen was reconstructed according to the following group assignments for biomechanical testing sequence at the operative levels (L2-3 and L4-5): 1)
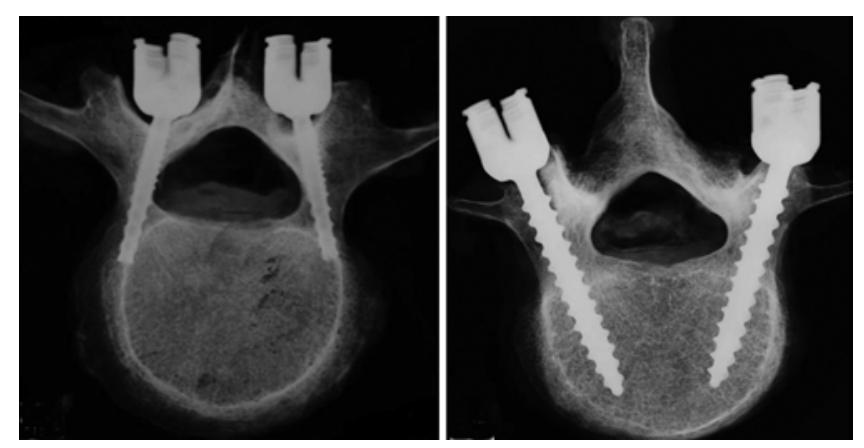

FIG. 1. Representative axial microradiographic images showing the comparative fixation techniques of cortical screw (left) versus transpedicular screw (right) placement in the lumbar vertebral elements. Note the difference in screw dimensions and diverging pathways for the cortical screw (left) versus the converging trajectory of the traditional pedicle screws (right).

intact spine; 2) destabilization by bilateral partial medial laminectomies and facetectomies (L2-3 and L4-5); 3) cortical versus pedicle screw reconstruction-randomized at all levels; 4) fatigue testing through 50,000 cycles (25,000 flexion-extension, 15,000 lateral bending, and 10,000 axial rotation); 5) fluoroscopy of reconstructions of the whole spine; 6) pullout testing of the individual screws following disarticulation of the operative levels.

A total of 8 lumbosacral spines underwent biomechanical testing in this investigation. The destabilization procedure consisted of posterior resection of the supraspinous ligament, interspinous ligament, and ligamentum flavum, with bilateral partial medial laminectomies at the L2-3 and L4-5 levels, followed by removal of bilateral L-2 and L-4 inferior articular facets. The L2-3 and L4-5 levels were then reconstructed using transpedicular or cortical screw fixation, which were randomized between the levels. All reconstructions were performed by a fellowshiptrained spine surgeon utilizing the largest pedicle or cortical screws that could be safely inserted. The dimensions of the pedicle screws were $6.0 \times 45 \mathrm{~mm}$ and $7.0 \times 45 \mathrm{~mm}$. The dimensions of the cortical screws were $4.35 \times 30 \mathrm{~mm}$ or $4.35 \times 35 \mathrm{~mm}$ and $5.0 \times 30 \mathrm{~mm}$ or $5.0 \times 35 \mathrm{~mm}$.

To define screw trajectory, pedicle screw insertion was performed following use of drill and Lenke probe; however, due to the osteoporotic condition of the tissues, the pedicles were not tapped prior to screw insertion. The cortical screw insertion point originated at the superior edge of the neuroforamen, approximately 3-4 $\mathrm{mm}$ medial to the superior articular facet. In all cortical screw cases, a pilot hole was created in the pars using a 3-mm-diameter drill, followed by insertion of the Lenke probe. The drill and probe were directed cephalad and laterally through the pars interarticularis and superior pedicle. Care was taken to avoid spinal canal compromise and violation of the lateral pedicle cortex when preparing the cortical screw tract. All reconstructions were performed using standard techniques, consistent screw dimensions, and manufacturer's guidelines (Fig. 2).

\section{Fatigue Exposure}

Nondestructive, multidirectional flexibility testing us- 

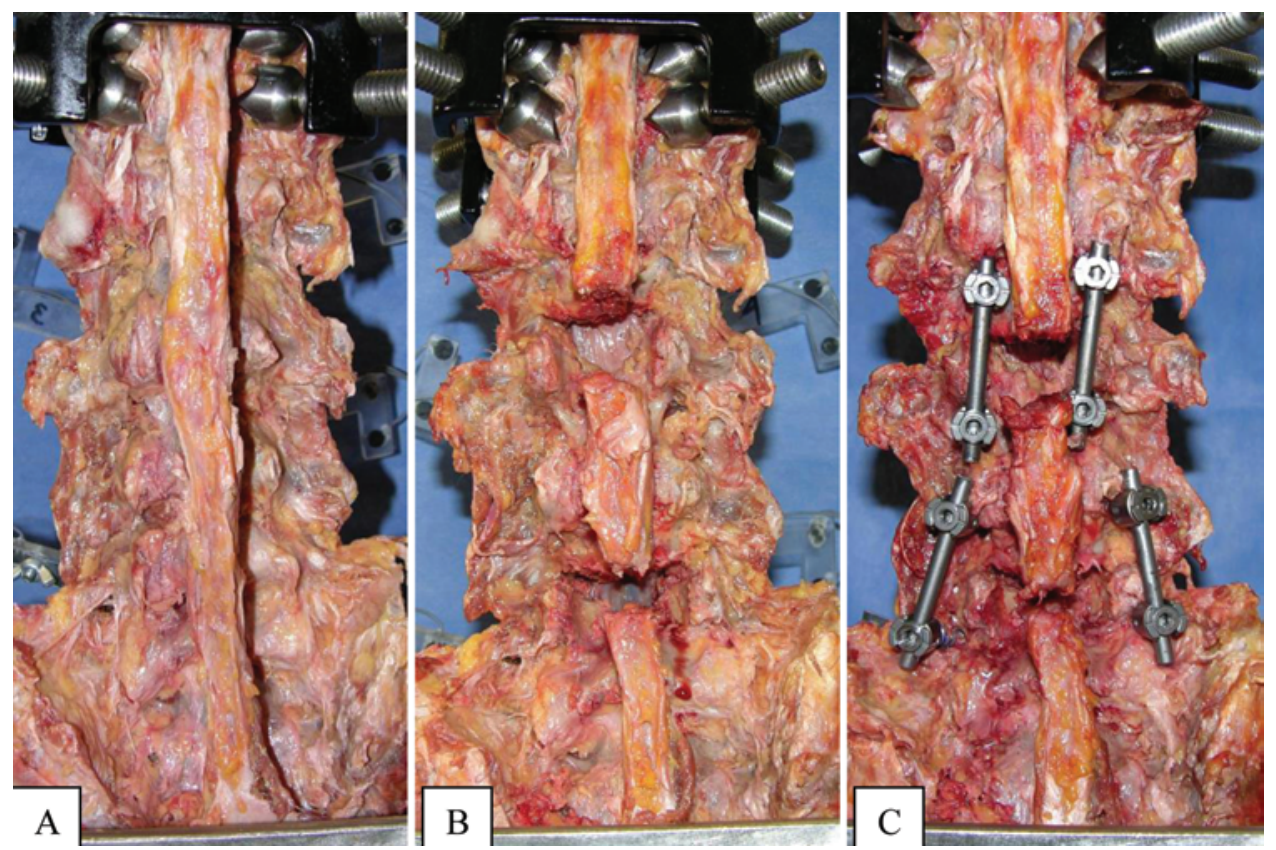

FIG. 2. Representative posterior views of the 3 testing conditions showing intact (A), destabilized (B), and reconstructed (C) lumbosacral specimen. Note: Reconstruction condition $\mathrm{C}$ underwent subsequent fatigue and pullout testing. Figure is available in color online only.

ing a custom-designed 6-degree-of-freedom spine simulator (6DOF-SS) was used to simulate the physiological loads $( \pm 8 \mathrm{~N} \cdot \mathrm{m})$ that lead to progressive screw failure. The 6DOF-SS gimbal apparatus was affixed to the superior portion of the specimen and permits unconstrained rotational motions about 3 independent axes: axial rotation (y-axis), flexion-extension (x-axis), and lateral bending (z-axis). The testing platform is attached to orthogonally positioned linear guide rails, permitting linear translations along the $\mathrm{x}$ - and $\mathrm{z}$-axes, while a pneumatic actuator allows for $y$-axis translations. Rotational moments were applied to the superior end of the vertically oriented specimen while the caudal portion of the specimen remained fixed to the testing platform (Fig. 3). The fatigue component consisted of 25,000 cycles of flexion-extension loading (x-axis, $\pm 2.0 \mathrm{~N} \cdot \mathrm{m}), 15,000$ cycles of lateral bending (z-axis, $\pm 2.0 \mathrm{~N} \cdot \mathrm{m}$ ), and 10,000 cycles of axial rotation (yaxis, $\pm 2.0 \mathrm{~N} \cdot \mathrm{m})$ at a frequency of $2.0 \mathrm{~Hz}$ using an MTS 858 Bionix Test System. The specimens were moistened using $0.9 \%$ saline irrigation solution throughout the testing procedures.

\section{Fluoroscopic Analysis}

Lateral high-resolution fluoroscopic images were obtained of the L2-3 and L4-5 reconstructions both before and after fatigue testing. These were used to qualitatively assess implant location, positional stability of the screws, and any incidence of screw migration secondary to the fatigue component (Fig. 4).

\section{Analysis of Radiolucency at the Screw-Bone Interface}

In addition to fluoroscopic imaging of the lumbar spine, the postfatigue disarticulated lumbar vertebral segments underwent Faxitron microradiography in the axial and sagittal planes to quantify radiolucency at the screw-bone interface. The segments were placed 12 inches from the beam and exposed for 3 minutes, using a technique of $65 \mathrm{kVp}$ and $3 \mathrm{~mA}$ while in contact with high-resolution graphic arts film. Based on screw length, the high-resolution axial microradiographs were used for assessment and quantification (\%) of radiolucency at the screw-bone interface using the ImageJ software program (Fig. 5).

\section{Pedicle and Cortical Screw Pullout Analysis}

Following fatigue loading, the lumbar specimens were carefully disarticulated into the L-2, L-3, L-4, and L-5 vertebral segments. The individual segments were then secured in rectangular tubing foundations using a stainless

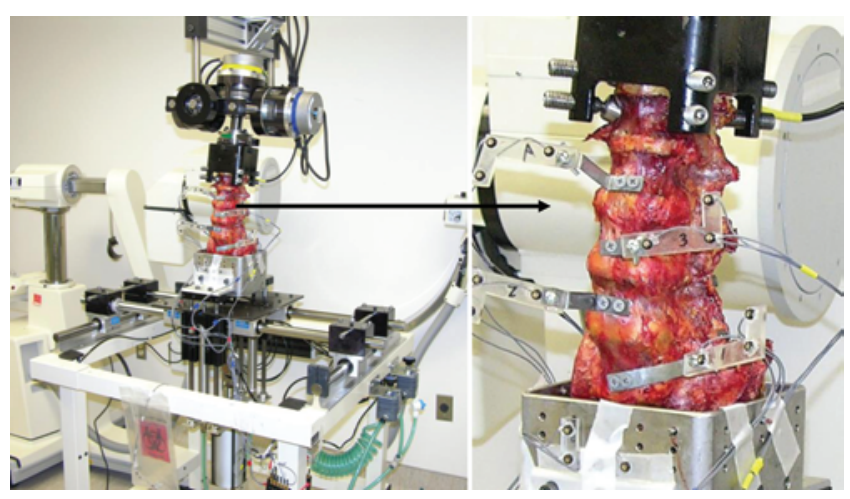

FIG. 3. Representative oblique photographs of an intact lumbosacral specimen prepared for 6DOF-SS fatigue testing. Figure is available in color online only. 


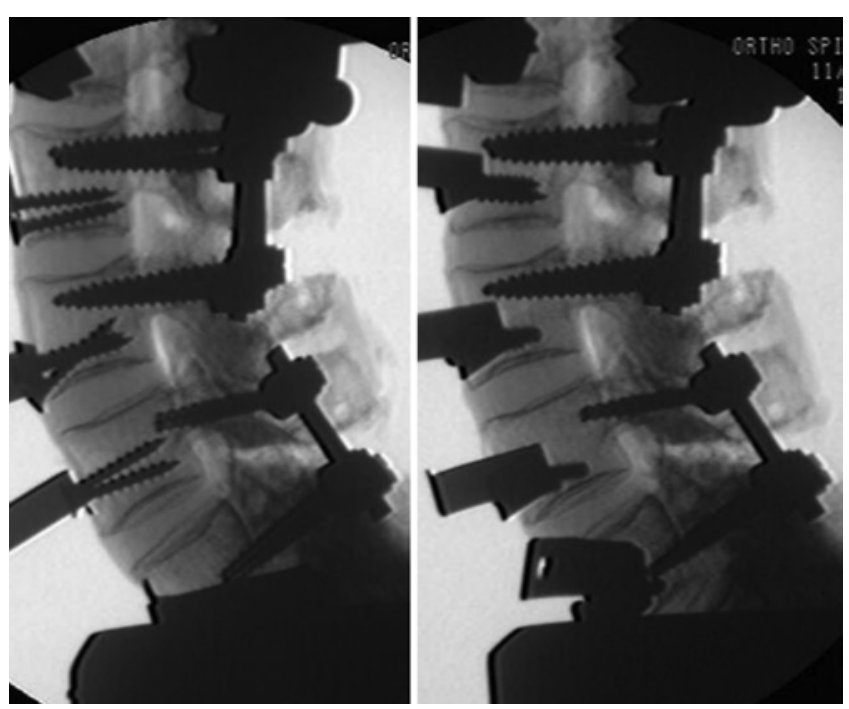

FIG. 4. Representative lateral fluoroscopic images showing the prefatigue (left) and postfatigue (right) conditions of the instrumentation procedures, with cortical screws at L4-5 and pedicle screws at L2-3 (Specimen 1).

steel rod placed through the container and 4-point compression screws (Fig. 6). The fixtures permitted placement of the specimen, as needed, to allow for the tensile pullout force to be directed along the long axis of each screw. Load to failure pullout testing of the cortical and pedicle screws was performed using a servohydraulic MTS 858 Bionix testing device (MTS Systems Inc.). The uniaxial tensile load to failure test was conducted at a rate of 0.25 $\mathrm{mm} / \mathrm{second}$ to the point of screw dislodgement or vertebral fracture. Load-displacement data acquisition was performed through an analog-to-digital DAS16G Metrabyte board (Metrabyte Corporation) at a rate of $10 \mathrm{~Hz}$ to a personal computer. All data files were downloaded into Excel for spreadsheet computational data analysis. The calculation of peak load (Newtons) at screw dislodgement and/or vertebral body fracture was quantified for each segment.
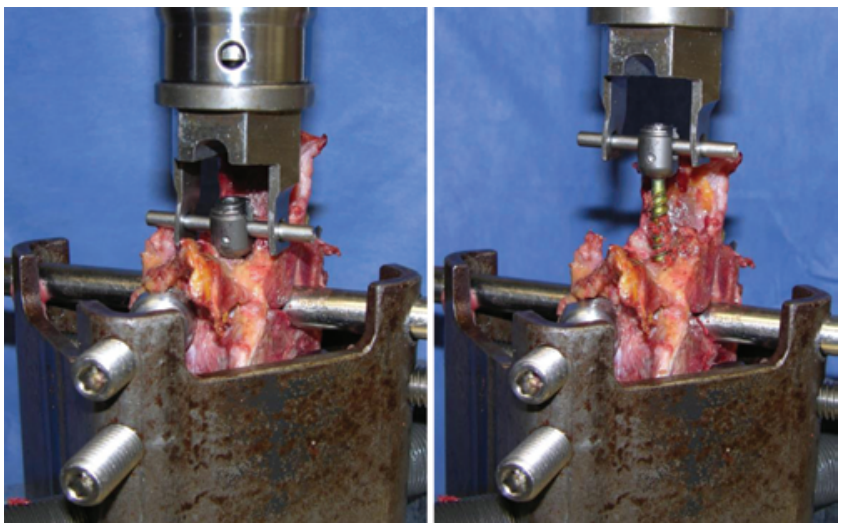

FIG. 6. Representative images of the vertebral fixation technique used for pedicle and cortical screw pullout analysis along the long axis of the screws. Left: A photograph showing the pedicle screw position prior to pullout. Right: A photograph taken following screw extraction and peak load registration. Importantly, vertebral rotational motion was prevented by the lateral compression screws while vertebral resistance to superior motion was achieved via the rod placed through the spinal canal. Figure is available in color online only.

\section{Data and Statistical Analysis}

Osteoporotic specimens were selected based on mean $\mathrm{T}$ scores (L-2 through L-5) less than or equal to -2.5 . For destructive pullout testing, the peak load at screw failure (Newtons) was calculated for each screw and averaged across treatments. The biomechanical pullout data (cortical vs pedicle) was stratified with regard to peak load at failure versus operative vertebral level and screw dimensions. Moreover, linear regression and correlation analysis was performed to determine the statistical relationship between vertebral BMD and mean failure loads of pedicle screws versus cortical screws. Statistical analysis includes descriptive statistics and a Wilcoxon-Mann-Whitney test for comparison of load at failure for each reconstruction condition. ANOVA with a post hoc Student-NewmanKeuls test was performed for comparisons among treatments.
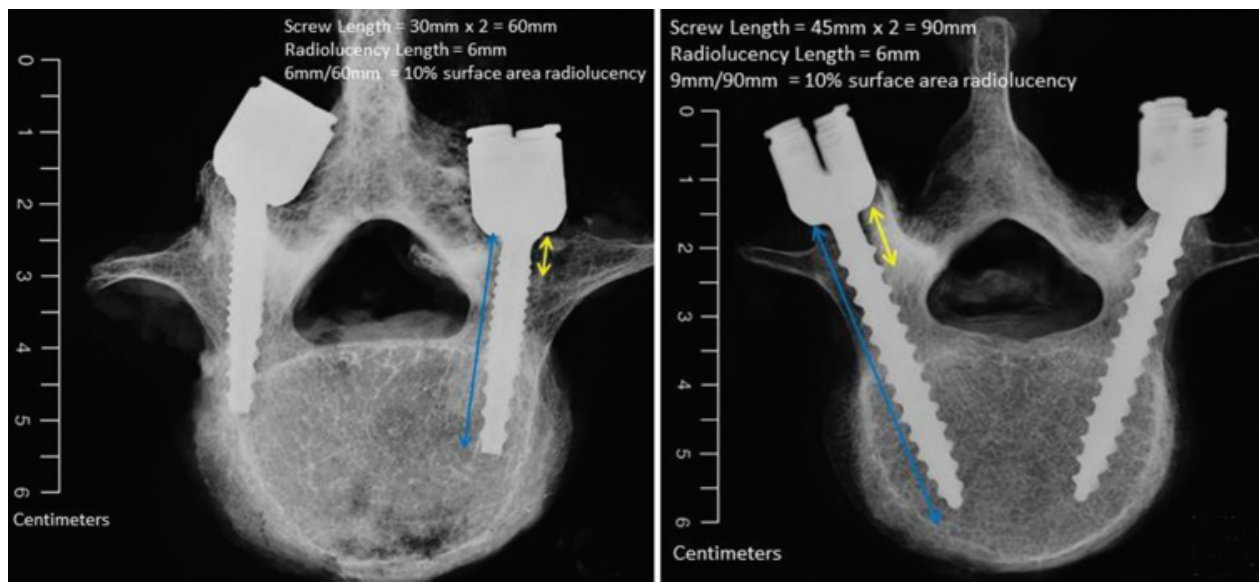

FIG. 5. Representative axial microradiographs showing cortical screw (left) and pedicle screw (right) placement. The axial microradiographs were used for percent quantification of radiolucency at the screw-bone interface using the ImageJ software program. Figure is available in color online only. 


\section{Results}

\section{Specimen Demographics and Reconstruction Instrumentation}

A total of 8 fresh-frozen human spinopelvic specimens (T10-ilium) (mean age 74.5 years, range 59-82 years) were harvested en bloc and used in the current investigation. The overall mean BMD for specimens was 0.817 $\mathrm{g} / \mathrm{cm}^{3}$ (range $0.648-0.905 \mathrm{~g} / \mathrm{cm}^{3}$ ) with a corresponding $\mathrm{T}$ score of -3.3 (range -4.9 to -2.8 ). The individualized operative levels, treatment procedure (cortical or pedicle screw), implanted screw dimensions, BMD, and T scores for each operative level are itemized in Table 1.

\section{Fluoroscopic Analysis}

Lateral high-resolution fluoroscopic images were obtained of the L2-3 and L4-5 reconstructions to qualitatively assess implant location and positional stability of the screws following fatigue testing. Based on review of the 8 specimens included in the current study, all surgical constructs were placed correctly, with no evidence of screw migration or radiolucency following fatigue testing (Fig. 4).

\section{Analysis of Implant Screw Radiolucency}

The disarticulated lumbar vertebral segments underwent Faxitron microradiography in the axial and sagittal planes to quantify radiolucency at the screw-bone interface. Gross evidence of radiolucency at the bone-screw interface was observed in $5(16 \%)$ of 32 pedicle screws and $3(9 \%)$ of 32 implanted cortical screws. Gap formation was observed at the pedicle regions, with little to no observed radiolucency within the vertebral bodies. Based upon quantitative analysis of the radiolucent gaps at the bonemetal interface, the cortical screws and pedicle screws demonstrated $11.3 \% \pm 5.1 \%$ and $12.2 \% \pm 4.4 \%$ of surface area radiolucency, respectively $(\mathrm{p}=0.800)($ Table 2$)$.

\section{Pedicle and Cortical Screw Pullout Analysis}

Following fatigue loading and fluoroscopic analysis of implant location, the lumbar specimens were carefully disarticulated into their respective L-2, L-3, L-4, and L-5 vertebral segments and prepared for tensile-load-tofailure pullout testing. A total of 32 screws were tested in each group (cortical and pedicle), with the 2 highest and lowest values from each group excluded from the statistical analysis. The peak mean load at failure for the pedicle screws was $578.3 \pm 335.6 \mathrm{~N}$ versus $475.7 \pm 236.8 \mathrm{~N}$ for cortical screws - a difference of $17.7 \%$. Statistical analysis indicated no difference between treatments $(\mathrm{p}=0.192)$.

\section{Peak Failure Loads-Data Stratification}

In addition to an overall review of the comparative peak failure loads afforded by pedicle and cortical screw fixation, the data points were further stratified to evaluate peak load at failure against vertebral BMD, operative vertebral level, and implant screw dimensions. Linear regression and correlation analysis of peak failure loads to vertebral element BMD indicated lack of statistical significance for cortical screws (fit $\mathrm{R}^{2}=0.070$, effect of model $\mathrm{p}$
TABLE 1. Treatment procedures, screw dimensions, BMD, and T scores for each operative level

\begin{tabular}{|c|c|c|c|c|c|c|}
\hline $\begin{array}{l}\text { Spec } \\
\text { No. }\end{array}$ & $\begin{array}{l}\text { Donor Age } \\
\text { in Yrs, Sex }\end{array}$ & Site & Screw Size & $\begin{array}{c}\text { Screw } \\
\text { Type }\end{array}$ & BMD & T Score \\
\hline \multirow[t]{4}{*}{1} & $82, F$ & $\begin{array}{l}\mathrm{L}-2 \\
\mathrm{Lt} \\
\mathrm{Rt}\end{array}$ & $\begin{array}{l}6 \times 45 \mathrm{~mm} \\
6 \times 45 \mathrm{~mm}\end{array}$ & $P$ & 0.833 & -3.1 \\
\hline & & $\begin{array}{l}\mathrm{L}-3 \\
\mathrm{Lt} \\
\mathrm{Rt}\end{array}$ & $\begin{array}{l}6 \times 45 \mathrm{~mm} \\
6 \times 45 \mathrm{~mm}\end{array}$ & $P$ & 0.844 & -3.0 \\
\hline & & $\begin{array}{r}\mathrm{L}-4 \\
\mathrm{Lt} \\
\mathrm{Rt}\end{array}$ & $\begin{array}{l}5 \times 30 \mathrm{~mm} \\
5 \times 30 \mathrm{~mm}\end{array}$ & C & 0.821 & -3.1 \\
\hline & & $\begin{array}{l}\mathrm{L}-5 \\
\mathrm{Lt} \\
\mathrm{Rt}\end{array}$ & $\begin{array}{l}5 \times 30 \mathrm{~mm} \\
5 \times 30 \mathrm{~mm}\end{array}$ & C & 0.909 & -2.8 \\
\hline \multirow[t]{4}{*}{2} & $69, \mathrm{M}$ & $\begin{array}{r}\mathrm{L}-2 \\
\mathrm{Lt} \\
\mathrm{Rt}\end{array}$ & $\begin{array}{l}4.35 \times 30 \mathrm{~mm} \\
4.35 \times 30 \mathrm{~mm}\end{array}$ & $C$ & 0.880 & -3.1 \\
\hline & & $\begin{array}{l}\mathrm{L}-3 \\
\mathrm{Lt} \\
\mathrm{Rt}\end{array}$ & $\begin{array}{l}4.35 \times 30 \mathrm{~mm} \\
4.35 \times 30 \mathrm{~mm}\end{array}$ & C & 0.902 & -2.8 \\
\hline & & $\begin{array}{r}\mathrm{L}-4 \\
\mathrm{Lt} \\
\mathrm{Rt}\end{array}$ & $\begin{array}{l}7 \times 45 \mathrm{~mm} \\
7 \times 45 \mathrm{~mm}\end{array}$ & $P$ & 0.812 & -3.5 \\
\hline & & $\begin{array}{r}\mathrm{L}-5 \\
\mathrm{Lt} \\
\mathrm{Rt}\end{array}$ & $\begin{array}{l}7 \times 45 \mathrm{~mm} \\
7 \times 45 \mathrm{~mm}\end{array}$ & $P$ & 0.823 & -3.4 \\
\hline \multirow[t]{4}{*}{3} & $79, \mathrm{M}$ & $\begin{array}{r}\mathrm{L}-2 \\
\mathrm{Lt} \\
\mathrm{Rt}\end{array}$ & $\begin{array}{l}6 \times 45 \mathrm{~mm} \\
6 \times 45 \mathrm{~mm}\end{array}$ & $P$ & 0.751 & -4.1 \\
\hline & & $\begin{array}{r}\mathrm{L}-3 \\
\mathrm{Lt} \\
\mathrm{Rt}\end{array}$ & $\begin{array}{l}6 \times 45 \mathrm{~mm} \\
6 \times 45 \mathrm{~mm}\end{array}$ & $P$ & 0.763 & -4.0 \\
\hline & & $\begin{array}{r}\mathrm{L}-4 \\
\mathrm{Lt} \\
\mathrm{Rt}\end{array}$ & $\begin{array}{l}4.35 \times 30 \mathrm{~mm} \\
4.35 \times 30 \mathrm{~mm}\end{array}$ & C & 0.804 & -3.6 \\
\hline & & $\begin{array}{l}\mathrm{L}-5 \\
\mathrm{Lt} \\
\mathrm{Rt}\end{array}$ & $\begin{array}{l}4.35 \times 30 \mathrm{~mm} \\
4.35 \times 30 \mathrm{~mm}\end{array}$ & $C$ & 0.711 & -3.8 \\
\hline \multirow[t]{4}{*}{4} & $59, \mathrm{~F}$ & $\begin{array}{l}\mathrm{L}-2 \\
\mathrm{Lt} \\
\mathrm{Rt}\end{array}$ & $\begin{array}{l}6 \times 45 \mathrm{~mm} \\
6 \times 45 \mathrm{~mm}\end{array}$ & $P$ & 1.015 & -1.6 \\
\hline & & $\begin{array}{l}\mathrm{L}-3 \\
\mathrm{Lt} \\
\mathrm{Rt}\end{array}$ & $\begin{array}{l}6 \times 45 \mathrm{~mm} \\
6 \times 45 \mathrm{~mm}\end{array}$ & $P$ & 0.867 & -2.8 \\
\hline & & $\begin{array}{r}\mathrm{L}-4 \\
\mathrm{Lt} \\
\mathrm{Rt}\end{array}$ & $\begin{array}{l}4.35 \times 30 \mathrm{~mm} \\
4.35 \times 30 \mathrm{~mm}\end{array}$ & $C$ & 0.796 & -3.3 \\
\hline & & $\begin{array}{l}\mathrm{L}-5 \\
\mathrm{Lt} \\
\mathrm{Rt}\end{array}$ & $\begin{array}{l}4.35 \times 30 \mathrm{~mm} \\
5 \times 30 \mathrm{~mm}^{*}\end{array}$ & $C$ & 0.770 & -3.4 \\
\hline
\end{tabular}

CONTINUED ON PAGE $472 »$ 
» CONTINUED FROM PAGE 471

TABLE 1. Treatment procedures, screw dimensions, BMD, and T scores for each operative level

\begin{tabular}{|c|c|c|c|c|c|c|}
\hline $\begin{array}{l}\text { Spec } \\
\text { No. }\end{array}$ & $\begin{array}{l}\text { Donor Age } \\
\text { in Yrs, Sex }\end{array}$ & Site & Screw Size & $\begin{array}{l}\text { Screw } \\
\text { Type }\end{array}$ & BMD & T Score \\
\hline \multirow[t]{4}{*}{5} & $82, F$ & $\begin{array}{l}\mathrm{L}-2 \\
\mathrm{Lt} \\
\mathrm{Rt}\end{array}$ & $\begin{array}{l}4.35 \times 30 \mathrm{~mm} \\
4.35 \times 30 \mathrm{~mm}\end{array}$ & C & 0.692 & -4.3 \\
\hline & & $\begin{array}{r}\mathrm{L}-3 \\
\mathrm{Lt} \\
\mathrm{Rt}\end{array}$ & $\begin{array}{l}4.35 \times 30 \mathrm{~mm} \\
4.35 \times 30 \mathrm{~mm}\end{array}$ & $C$ & 0.760 & -3.7 \\
\hline & & $\begin{array}{r}\mathrm{L}-4 \\
\mathrm{Lt} \\
\mathrm{Rt}\end{array}$ & $\begin{array}{l}6 \times 45 \mathrm{~mm} \\
6 \times 45 \mathrm{~mm}\end{array}$ & $P$ & 0.793 & -3.3 \\
\hline & & $\begin{array}{r}\mathrm{L}-5 \\
\mathrm{Lt} \\
\mathrm{Rt}\end{array}$ & $\begin{array}{l}6 \times 45 \mathrm{~mm} \\
6 \times 45 \mathrm{~mm}\end{array}$ & $P$ & 0.904 & -2.3 \\
\hline \multirow[t]{4}{*}{6} & $72, \mathrm{M}$ & $\begin{array}{l}\mathrm{L}-2 \\
\mathrm{Lt} \\
\mathrm{Rt}\end{array}$ & $\begin{array}{l}4.35 \times 30 \mathrm{~mm} \\
4.35 \times 30 \mathrm{~mm}\end{array}$ & C & 0.832 & -3.5 \\
\hline & & $\begin{array}{l}\mathrm{L}-3 \\
\mathrm{Lt} \\
\mathrm{Rt}\end{array}$ & $\begin{array}{l}5 \times 30 \mathrm{~mm} \\
5 \times 30 \mathrm{~mm}\end{array}$ & $C$ & 0.883 & -3.0 \\
\hline & & $\begin{array}{l}\mathrm{L}-4 \\
\mathrm{Lt} \\
\mathrm{Rt}\end{array}$ & $\begin{array}{l}6 \times 45 \mathrm{~mm} \\
6 \times 45 \mathrm{~mm}\end{array}$ & $P$ & 0.956 & -2.4 \\
\hline & & $\begin{array}{l}\mathrm{L}-5 \\
\mathrm{Lt} \\
\mathrm{Rt}\end{array}$ & $\begin{array}{l}7 \times 45 \mathrm{~mm} \\
7 \times 45 \mathrm{~mm}\end{array}$ & $P$ & 0.949 & -2.4 \\
\hline \multirow[t]{4}{*}{7} & $79, \mathrm{M}$ & $\begin{array}{r}\mathrm{L}-2 \\
\mathrm{Lt} \\
\mathrm{Rt}\end{array}$ & $\begin{array}{l}4.35 \times 35 \mathrm{~mm} \\
4.35 \times 35 \mathrm{~mm}\end{array}$ & $C$ & 0.635 & -5.1 \\
\hline & & $\begin{array}{l}\mathrm{L}-3 \\
\mathrm{Lt} \\
\mathrm{Rt}\end{array}$ & $\begin{array}{l}5 \times 35 \mathrm{~mm} \\
5 \times 35 \mathrm{~mm}\end{array}$ & $C$ & 0.690 & -4.5 \\
\hline & & $\begin{array}{l}\mathrm{L}-4 \\
\mathrm{Lt} \\
\mathrm{Rt}\end{array}$ & $\begin{array}{l}6 \times 45 \mathrm{~mm} \\
6 \times 45 \mathrm{~mm}\end{array}$ & $P$ & 0.643 & -4.8 \\
\hline & & $\begin{array}{l}\mathrm{L}-5 \\
\mathrm{Lt} \\
\mathrm{Rt}\end{array}$ & $\begin{array}{l}7 \times 45 \mathrm{~mm} \\
7 \times 45 \mathrm{~mm}\end{array}$ & $P$ & 0.625 & -5.1 \\
\hline \multirow[t]{4}{*}{8} & $74, F$ & $\begin{array}{l}\mathrm{L}-2 \\
\mathrm{Lt} \\
\mathrm{Rt}\end{array}$ & $\begin{array}{l}4.35 \times 35 \mathrm{~mm} \\
4.35 \times 35 \mathrm{~mm}\end{array}$ & $C$ & 0.759 & -3.7 \\
\hline & & $\begin{array}{l}\mathrm{L}-3 \\
\mathrm{Lt} \\
\mathrm{Rt}\end{array}$ & $\begin{array}{l}5 \times 35 \mathrm{~mm} \\
5 \times 35 \mathrm{~mm}\end{array}$ & C & 0.811 & -3.2 \\
\hline & & $\begin{array}{l}\mathrm{L}-4 \\
\mathrm{Lt} \\
\mathrm{Rt}\end{array}$ & $\begin{array}{l}6 \times 45 \mathrm{~mm} \\
6 \times 45 \mathrm{~mm}\end{array}$ & $P$ & 0.849 & -2.9 \\
\hline & & $\begin{array}{l}\mathrm{L}-5 \\
\mathrm{Lt} \\
\mathrm{Rt}\end{array}$ & $\begin{array}{l}7 \times 45 \mathrm{~mm} \\
7 \times 45 \mathrm{~mm}\end{array}$ & $P$ & 0.929 & -2.1 \\
\hline
\end{tabular}

$C=$ cortical $; P=$ pedicle $;$ Spec $=$ specimen.

* The right L-5 pedicle screw size was $5 \times 30 \mathrm{~mm}$ due to a lack of availability of a $4.35 \times 30-\mathrm{mm}$ screw.
$=0.172$ ) and pedicle screws (fit $\mathrm{R}^{2}=0.061$, effect of model $\mathrm{p}=0.203)$ (Figs. 7 and 8).

When stratified by operative level, there was a discernible difference in the trends of peak load at failure afforded by cortical versus pedicle screws. Cortical fixation exhibited a marked increase in mean load at failure in the lower vertebral segments $(p=0.188,625.6 \pm 233.4 \mathrm{~N}$ vs $450.7 \pm 204.3 \mathrm{~N}$ at L-4 and $p=0.219,640.9 \pm 207.4 \mathrm{~N}$ vs $519.3 \pm 132.1 \mathrm{~N}$ at L-5), while transpedicular screw fixation demonstrated a reverse trend of decreased failure in the lower vertebral elements and higher failure loads in the upper vertebral elements $(\mathrm{p}=0.024,783.0 \pm 516.1 \mathrm{~N}$ vs $338.4 \pm 168.2 \mathrm{~N}$ at $\mathrm{L}-2$ and $\mathrm{p}=0.220,723.0 \pm 492.9 \mathrm{~N}$ vs $469.8 \pm 252.0 \mathrm{~N}$ at L-3). While not statistically significant, the strength of cortical fixation at L-5 was approaching significance when compared with L-2 (Fig. 9).

When stratified by screw dimensions, there were no differences in the trends of peak failure loads afforded by cortical versus pedicle screws. Although smaller in mean diameter (4.35 mm vs $6.0 \mathrm{~mm})$ and length $(30 \mathrm{~mm}$ vs 45 $\mathrm{mm}$ ), posterior cortical fixation indicated mean loads at failure that were not significantly different from pedicle screws of larger dimension $(\mathrm{p}>0.05,449.4 \pm 265.3 \mathrm{~N}$ and $541.2 \pm 135.1 \mathrm{~N}$ vs $616.0 \pm 384.5 \mathrm{~N}$ and $484.0 \pm 137.1 \mathrm{~N}$, respectively) (Fig. 10).

\section{Discussion}

Millions of patients with degenerative spinal disease secondary to osteoporosis experience screw loosening, pullout, and instrumentation failure following lumbar arthrodesis. ${ }^{11,13,17,25}$ Conventional transpedicular fixation has long been the standard of care, but poor screw-bone purchase secondary to reduced cancellous bone mass may severely limit its fixation potential in patients suffering from osteoporosis. Novel strategies in spinal fixation techniques that maximize cortical purchase may improve surgical outcomes and quality of life for these patients with osteoporosis. In contrast to pedicle screw fixation, cortical screws are designed to purchase the pedicle through the pars interarticularis with a medial to lateral trajectory, eccentrically placing the screw to solely engage cortical bone within the pedicle with no involvement of the cancellous space. This trajectory theoretically maximizes the purchase of cortical bone and potentially improves longterm fixation. With this approach in mind, the current study is the first to compare cortical versus pedicle screw fixation following physiological stress in the osteoporotic lumbar spine.

The fixation properties of cortical and pedicle screws were evaluated via pullout analysis, which has traditionally characterized screw-bone interface quality by comparing peak failure loads between 2 surgical constructs. ${ }^{3,6,11,12,19,21,23}$ To further model the physiological conditions in which spinal instrumentation fails, pullout analysis was preceded by extensive fatigue testing. Prior studies have evaluated the mechanical integrity of cortical and pedicle screw fixation under static, uniaxial conditions, ${ }^{22}$ but few have attempted to simulate the physiological loads experienced in the postoperative phase. Sterba and colleagues ${ }^{24}$ recommended using nondestructive, compressive cyclic loading of lum- 


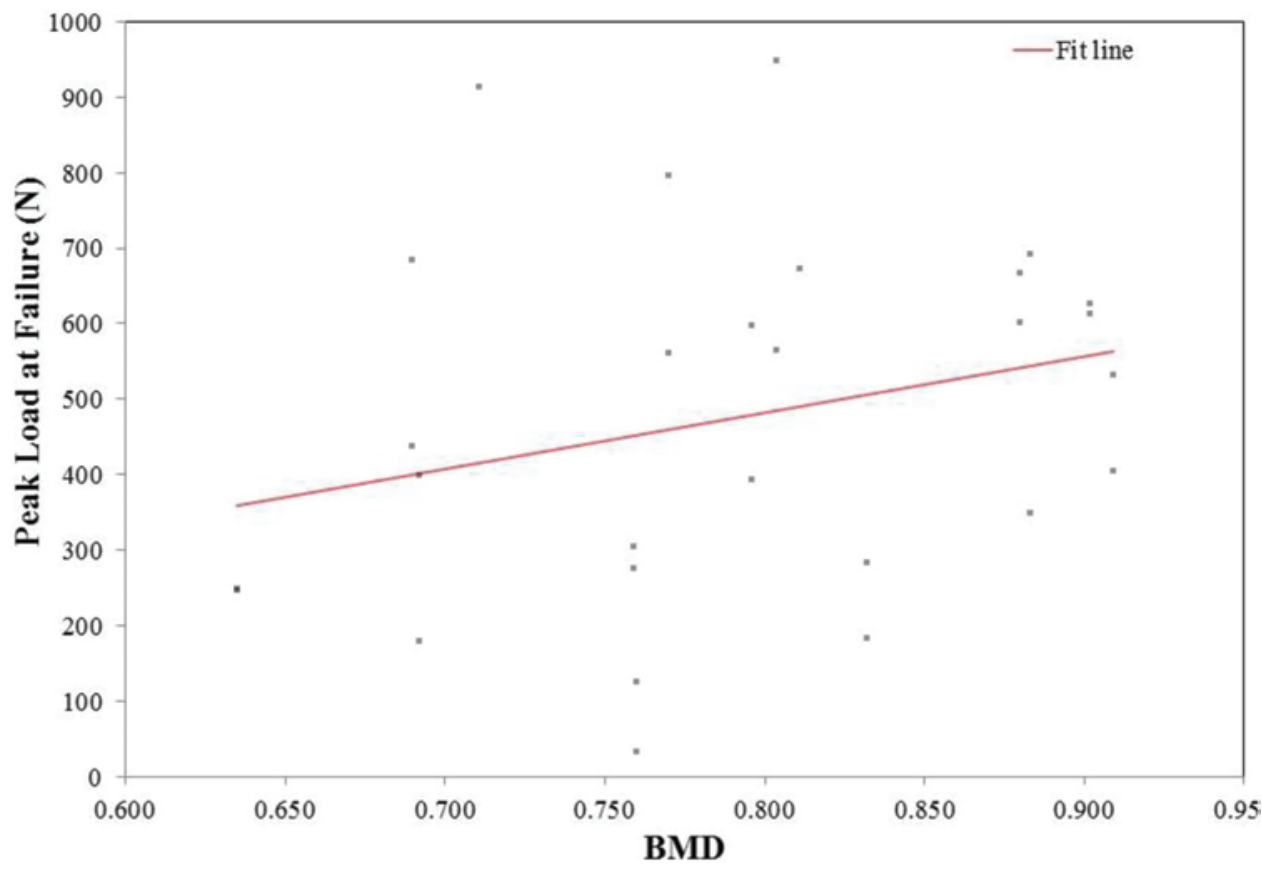

Fit

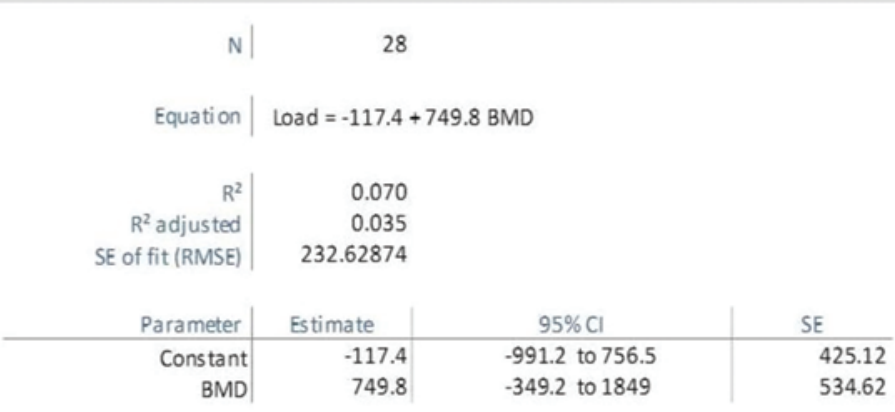

Effect of Model

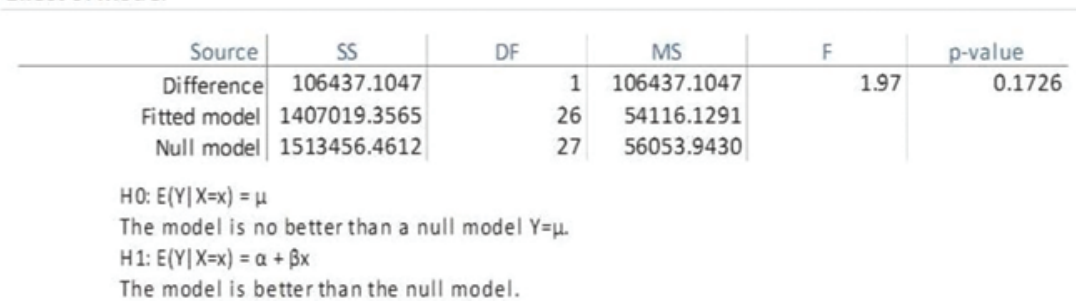

FIG. 7. Linear regression (upper) and correlation analysis (lower) for cortical screws comparing peak load at screw failure versus $\mathrm{BMD}$. The high distribution of variability in peak failure loads with correspondingly low BMD values most likely accounts for the lack of statistical significance in this comparison $(p=0.1726)$. MS = mean square; SE = standard error; $S S=$ sum of squares. Figure is available in color online only.

bar pedicle screws while Burval et al. ${ }^{5}$ reported a testing regimen consisting of 5000 cycles of fatigue conditioning before uniaxial pullout analysis. Our model placed the surgical constructs through 50,000 cycles of fatigue, divided among 3 axes, clearly exceeding current standards for sufficient fatigue exposure and possibly providing a better model of physiological conditions in the postoperative period leading up to construct failure.

The fixation properties of cortical and pedicle screws were dependent upon the vertebral level instrumented. When the pullout data were stratified against operative level, cortical screw fixation exhibited a marked increase in mean load at failure in the lower lumbar segments. Interestingly, transpedicular screw fixation demonstrated a reverse trend of lower failure loads in the inferior vertebral elements and higher failure loads in the superior vertebral elements, likely secondary to the unique pedicle composition in the lumbar spine. Cadaveric analysis routinely shows the pedicle width of lumbar vertebrae to gradually increase from L-1 to L-4, with a sharp increase at L-5, while pedicle height of lumbar vertebrae remain fairly constant,,${ }^{14}$ consistent with prior imaging-based stud- 


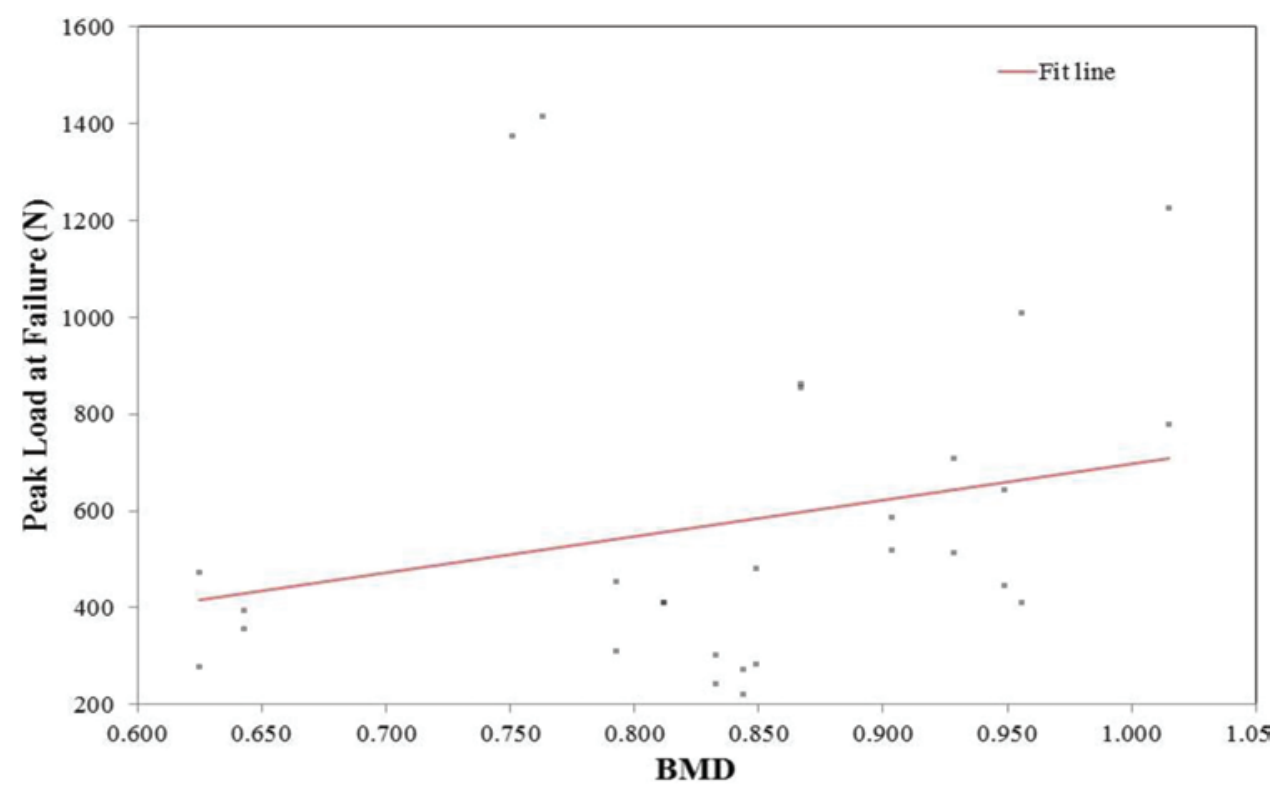

Fit

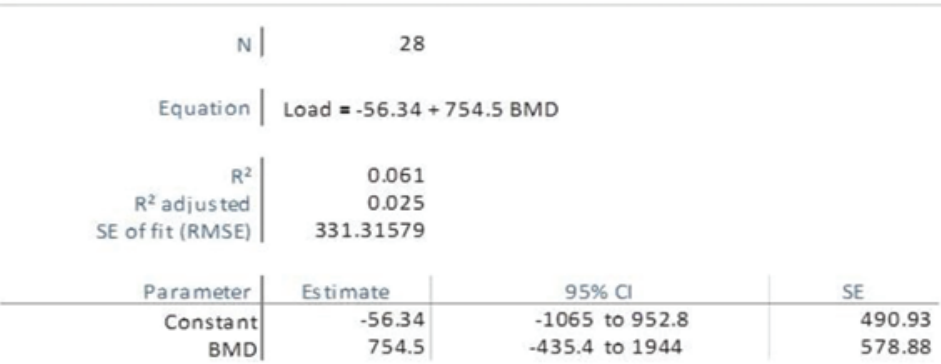

Effect of Model

\begin{tabular}{r|r|r|r|r|r} 
Source & \multicolumn{1}{|c}{ SS } & DF & MS & F & p-value \\
\hline Difference & 186485.8240 & 1 & 186485.8240 & 1.70 & 0.2039 \\
Fitted model & 2854023.9661 & 26 & 109770.1525 & & \\
Null model & 3040509.7901 & & 27 & 112611.4737 & \\
\end{tabular}

$H O: E(Y \mid X=x)=\mu$

The model is no better than a null model $Y=\mu$.

$H 1: E(Y \mid X=x)=\alpha+\beta x$

The model is better than the null model.

FIG. 8. Linear regression (upper) and correlation analysis (lower) for pedicle screws comparing peak load at screw failure versus BMD. The high distribution of variability in peak failure loads with correspondingly low BMD values most likely accounts for the lack of statistical significance in this comparison $(p=0.2039)$. Figure is available in color online only.

TABLE 2. Percentage radiolucency at the bone-screw interface*

\begin{tabular}{|c|c|c|c|c|c|c|c|}
\hline $\begin{array}{l}\text { Spec } \\
\text { No. }\end{array}$ & Level & $\begin{array}{l}\text { Screw } \\
\text { Type }\end{array}$ & $\begin{array}{l}\text { Screw Length } \\
(\mathrm{mm})\end{array}$ & $\begin{array}{l}\text { Size of Radiolucent } \\
\text { Gap (mm) }\end{array}$ & $\begin{array}{l}\text { Mean Size of Radiolucent } \\
\text { Gaps (mm) }\end{array}$ & \% Radiolucency & $\begin{array}{c}\text { Mean \% } \\
\text { Radiolucency }\end{array}$ \\
\hline 1 & $L-4$ & C & $5 \times 30=60$ & 6 & \multirow{3}{*}{$7.0 \pm 2.6$} & 10.0 & \multirow{3}{*}{$11.3 \pm 5.1$} \\
\hline 1 & $L-5$ & C & $5 \times 35=70$ & 5 & & 7.0 & \\
\hline 5 & L-3 & C & $4.35 \times 30=60$ & 10 & & 17.0 & \\
\hline 5 & L-4 & $P$ & $6 \times 45=90$ & 15 & \multirow{5}{*}{$10.8 \pm 3.9$} & 17.0 & \multirow{5}{*}{$12.2 \pm 4.44$} \\
\hline 6 & $L-5$ & $P$ & $7 \times 45=90$ & 7 & & 8.0 & \\
\hline 7 & $\mathrm{~L}-4$ & $P$ & $6 \times 45=90$ & 8 & & 9.0 & \\
\hline 7 & $L-5$ & $P$ & $7 \times 45=90$ & 9 & & 10.0 & \\
\hline 8 & $L-5$ & $P$ & $7 \times 45=90$ & 15 & & 17.0 & \\
\hline
\end{tabular}

${ }^{*}$ Mean values are given with SDs. 


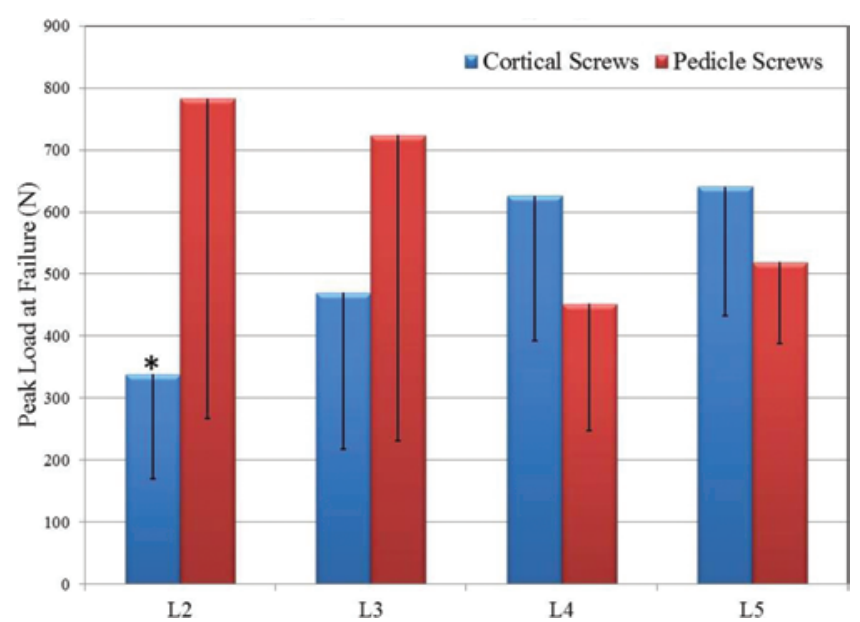

FIG. 9. Bar graph comparing the peak load of screw pullout data for cortical screws versus pedicle screws stratified according to operative level, $\mathrm{L}-2, \mathrm{~L}-3, \mathrm{~L}-4$, and $\mathrm{L}-5$. Note the reversed trends of mean failure loads and biomechanical advantages of cortical fixation in the lower lumbar vertebral elements versus transpedicular screw fixation. *Indicates significance versus $L-5$ operative level based on ANOVA ( $F=3.02$, $p$ $=0.0492$ ). Bars indicate mean values and error bars minus 1 standard deviation. Figure is available in color online only.

ies. ${ }^{18,26}$ Taken together, pedicle volume gradually increases from L-1 to L-5, predominantly secondary to an increase in cancellous bone volume. At higher vertebral segments, transpedicular fixation may compensate for these anatomical characteristics via optimal filling of the pedicle and purchase of the dense outer cortical bone, leading to higher pullout strengths. However, with progression caudally down the lumbar pedicles, optimal cortical bone purchase diminishes due to the increased ratio of cancellous to cortical bone. Traditional pedicle screws in the caudal lumbar segments are thus more likely to purchase cancellous bone. In osteoporotic patients, cancellous bone loses significant mass and stability, exaggerating the inferior screw-bone interface characteristic of pedicle trajectory screws and predisposing transpedicular fixation to instrumentation loosening and pullout. Cortical screws are minimally affected by the enhanced cancellous properties of inferior osteoporotic lumbar pedicles because they target the highly dense cortical bone, which is mostly spared by the osteoporotic disease process. With a cortical trajectory, screws can thus achieve adequate fixation, where the conventional transpedicular approach may be limited, even with a smaller screw. In fact, our study revealed equivalent pullout strength of cortical fixation despite a $30 \%$ reduction in screw length and diameter when compared with transpedicular fixation.

This study, however, has several limitations. While the transpedicular and cortical screw constructs were placed by a fellowship-trained spine surgeon, a free-handed technique was used, resulting in relative variability in final screw positioning. Future endeavors could rectify this limitation by using image guidance to aid in screw placement. Analyzing a relatively small number of specimens also potentially limited the power of this study and precluded statistical significance in many of our findings. Without stratification, there were no statistically significant differ-

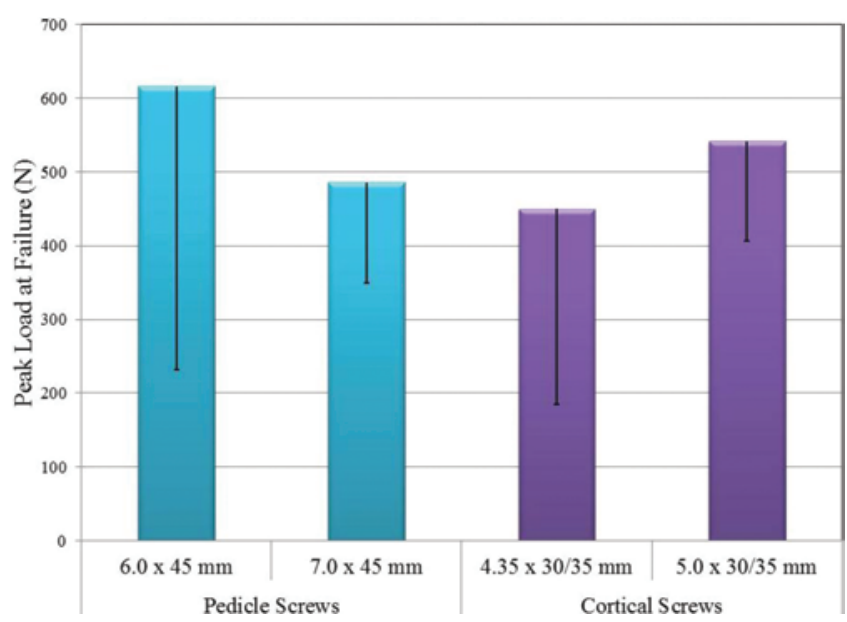

FIG. 10. Bar graph comparing the peak load of screw pullout data for cortical screws versus pedicle screws stratified according to screw dimension. The mean peak failure loads were not statistically different between screw types, despite the marked differences in screw dimensions and regions of fixation $(p>0.05)$. Bars indicate mean values and error bars minus 1 standard deviation. Figure is available in color online only.

ences between cortical and pedicle screw fixation, and the peak failure loads indicated high variability. Additionally, although common in the literature, clinical failure of surgical constructs is multifactorial, where shear and bending loads are superimposed on uniaxial traction force.$^{15}$ While our model incorporated multidimensional fatigue testing prior to uniaxial pullout analysis, biomechanical models that incorporate additional physiological loads may provide a more clinically accurate representation of implant failure.

\section{Conclusions}

Adequate spinal fixation in patients with significant osteoporotic vertebral degeneration remains a significant challenge to spinal surgeons. The current investigation attempted to evaluate the efficacy of cortical screws as an alternative to standard pedicle screw fixation, using uniaxial pullout analysis as a proxy for screw-bone purchase and fixation strength following extensive multidimensional fatigue loading. The current results demonstrated that cortical screws improved fixation at lower lumbar vertebrae while standard transpedicular fixation resulted in greater pullout strength at higher lumbar vertebrae. These results, combined with the ability to minimize soft tissue dissection, pain, and blood loss with a cortical approach, make cortical screw fixation a viable alternative to a conventional transpedicular fixation, particularly for patients suffering from significant osteoporosis in the lower lumbar spine.

\section{References}

1. Aldini NN, Fini M, Giavaresi G, Giardino R, Greggi T, Parisini P: Pedicular fixation in the osteoporotic spine: a pilot in vivo study on long-term ovariectomized sheep. J Orthop Res 20:1217-1224, 2002

2. Anderson GF, Hussey PS: Population aging: a comparison 
among industrialized countries. Health Aff (Millwood) 19:191-203, 2000

3. Bai B, Kummer FJ, Spivak J: Augmentation of anterior vertebral body screw fixation by an injectable, biodegradable calcium phosphate bone substitute. Spine (Phila Pa 1976) 26:2679-2683, 2001

4. Baluch DA, Patel AA, Lullo B, Havey RM, Voronov LI, Nguyen NL, et al: Effect of physiological loads on cortical and traditional pedicle screw fixation. Spine (Phila Pa 1976) 39:E1297-E1302, 2014

5. Burval DJ, McLain RF, Milks R, Inceoglu S: Primary pedicle screw augmentation in osteoporotic lumbar vertebrae: biomechanical analysis of pedicle fixation strength. Spine (Phila Pa 1976) 32:1077-1083, 2007

6. Cook SD, Salkeld SL, Stanley T, Faciane A, Miller SD: Biomechanical study of pedicle screw fixation in severely osteoporotic bone. Spine J 4:402-408, 2004

7. Davne SH, Myers DL: Complications of lumbar spinal fusion with transpedicular instrumentation. Spine (Phila Pa 1976) 17 (6 Suppl):S184-S189, 1992

8. Esses SI, Sachs BL, Dreyzin V: Complications associated with the technique of pedicle screw fixation. A selected survey of ABS members. Spine (Phila Pa 1976) 18:2231-2239, 1993

9. Fini M, Giavaresi G, Greggi T, Martini L, Aldini NN, Parisini $\mathrm{P}$, et al: Biological assessment of the bone-screw interface after insertion of uncoated and hydroxyapatite-coated pedicular screws in the osteopenic sheep. J Biomed Mater Res A 66:176-183, 2003

10. Gilbert SG, Johns PC, Chow DC, Black RC: Relation of vertebral bone screw axial pullout strength to quantitative computed tomographic trabecular bone mineral content. J Spinal Disord 6:513-521, 1993

11. Halvorson TL, Kelley LA, Thomas KA, Whitecloud TS III, Cook SD: Effects of bone mineral density on pedicle screw fixation. Spine (Phila Pa 1976) 19:2415-2420, 1994

12. Hasegawa T, Inufusa A, Imai Y, Mikawa Y, Lim TH, An HS: Hydroxyapatite-coating of pedicle screws improves resistance against pull-out force in the osteoporotic canine lumbar spine model: a pilot study. Spine J 5:239-243, 2005

13. Hirano T, Hasegawa K, Takahashi HE, Uchiyama S, Hara T, Washio T, et al: Structural characteristics of the pedicle and its role in screw stability. Spine (Phila Pa 1976) 22:25042510, 1997

14. Lien SB, Liou NH, Wu SS: Analysis of anatomic morphometry of the pedicles and the safe zone for through-pedicle procedures in the thoracic and lumbar spine. Eur Spine J 16:1215-1222, 2007

15. McLain RF, McKinley TO, Yerby SA, Smith TS, SarigulKlijn N: The effect of bone quality on pedicle screw loading in axial instability. A synthetic model. Spine (Phila Pa 1976) 22:1454-1460, 1997

16. Moore DC, Maitra RS, Farjo LA, Graziano GP, Goldstein SA: Restoration of pedicle screw fixation with an in situ setting calcium phosphate cement. Spine (Phila Pa 1976) 22:1696-1705, 1997

17. Okuyama K, Sato K, Abe E, Inaba H, Shimada Y, Murai H: Stability of transpedicle screwing for the osteoporotic spine. An in vitro study of the mechanical stability. Spine (Phila Pa 1976) 18:2240-2245, 1993

18. Olsewski JM, Simmons EH, Kallen FC, Mendel FC, Severin CM, Berens DL: Morphometry of the lumbar spine: anatomical perspectives related to transpedicular fixation. J Bone Joint Surg Am 72:541-549, 1990
19. Renner SM, Lim TH, Kim WJ, Katolik L, An HS, Andersson GB: Augmentation of pedicle screw fixation strength using an injectable calcium phosphate cement as a function of injection timing and method. Spine (Phila Pa 1976) 29:E212E216, 2004

20. Sandén B, Olerud C, Johansson C, Larsson S: Improved bone-screw interface with hydroxyapatite coating: an in vivo study of loaded pedicle screws in sheep. Spine (Phila Pa 1976) 26:2673-2678, 2001

21. Sandén B, Olerud C, Larsson S: Hydroxyapatite coating enhances fixation of loaded pedicle screws: a mechanical in vivo study in sheep. Eur Spine J 10:334-339, 2001

22. Santoni BG, Hynes RA, McGilvray KC, Rodriguez-Canessa G, Lyons AS, Henson MA, et al: Cortical bone trajectory for lumbar pedicle screws. Spine J 9:366-373, 2009

23. Sarzier JS, Evans AJ, Cahill DW: Increased pedicle screw pullout strength with vertebroplasty augmentation in osteoporotic spines. J Neurosurg 96 (3 Suppl):309-312, 2002

24. Sterba W, Kim DG, Fyhrie DP, Yeni YN, Vaidya R: Biomechanical analysis of differing pedicle screw insertion angles. Clin Biomech (Bristol, Avon) 22:385-391, 2007

25. Wittenberg RH, Shea M, Swartz DE, Lee KS, White AA III, Hayes WC: Importance of bone mineral density in instrumented spine fusions. Spine (Phila Pa 1976) 16:647-652, 1991

26. Zindrick MR, Wiltse LL, Doornik A, Widell EH, Knight GW, Patwardhan AG, et al: Analysis of the morphometric characteristics of the thoracic and lumbar pedicles. Spine (Phila Pa 1976) 12:160-166, 1987

\section{Disclosures}

Dr. Sansur reports being a consultant for Depuy Synthes, Stryker, and Medtronic and receiving honoraria from Globus Medical, Inc., for teaching. Dr. Ibrahimi reports being a consultant for Globus Medical, Inc. Ms. Murgatroyd reports being an employee at Globus Medical, Inc. Dr. Cunningham reports being an employee at Globus Medical, Inc., and receiving grants related to this work from DePuy Synthes.

\section{Author Contributions}

Conception and design: Sansur, Ibrahimi, Cunningham. Acquisition of data: Sansur, Caffes, Murgatroyd, Cunningham. Analysis and interpretation of data: Sansur, Ibrahimi, Pratt, Murgatroyd, Cunningham. Drafting the article: Sansur, Caffes, Pratt, Lewis. Critically revising the article: Sansur, Caffes, Ibrahimi, Pratt, Lewis, Cunningham. Reviewed submitted version of manuscript: all authors. Approved the final version of the manuscript on behalf of all authors: Sansur. Statistical analysis: Murgatroyd, Cunningham. Administrative/technical/material support: Sansur, Cunningham. Study supervision: Sansur, Cunningham.

\section{Supplemental Information}

\section{Previous Presentations}

Portions of this work were presented in 2014 at the Congress of Neurological Surgeons, October 18-22, Boston, Massachusetts.

\section{Correspondence}

Charles A. Sansur, Department of Neurosurgery, 22 S Greene St., Ste. S12D, Baltimore, MD 21201-1595. email: csansur@smail. umaryland.edu. 